\title{
Biologia e pesca do camarão sete-barbas Xiphopenaeus kroyeri (Heller) (Crustacea, Penaeidae), na Armação do Itapocoroy, Penha, Santa Catarina, Brasil
}

\author{
Joaquim O. Branco \\ ${ }^{1}$ Centro de Ensino em Ciências Tecnológicas da Terra e do Mar, Universidade do Vale do Itajaí. Caixa Postal 360, \\ 88301-970 Itajaí, Santa Catarina, Brasil. E-mail: branco@univali.br
}

\begin{abstract}
Fishery and Biology of the sea-bob-shrimp Xiphopenaeus kroyeri (Heller) (Crustacea, Penaeidae), at Armação do Itapocoroy, Penha, Santa Catarina, Brazil. The artisanal fishery of the sea-bob-shrimp is known as "sun to sun fishery" and is developed in large scale along the Brazilian coast, playing a significant economic, historical, social and cultural role. Nowadays, sea-bob-shrimp fisheries is classified as the highest economic interest and the second fisheries resource in the South-southeast coast of Brazil. Aiming to study the biology and fishery of the sea-bob-shrimp at Armação do Itapocoroy, Penha $\left(26^{\circ} 40^{\prime}-26^{\circ} 47^{\prime} \mathrm{S}\right.$ and $\left.48^{\circ} 36^{\prime}-48^{\circ} 38^{\prime} \mathrm{W}\right), 30$ minutes samples were performed monthly, from August 1996 to July 2003. Total and standard length, sex, maturation stages, biomass and total number of specimens were registered between 1996-1997 and 1999-2001. Between August 1998 and July 1999, the diet of X. kroyeri (Heller, 1862) was also studied. The species' total length varied from 3.0 to $16.0 \mathrm{~cm}$ and seasonal fluctuations in its abundance and biomass showed higher values along the summer and autumn months. The length/weight relationship indicated an isometric growth and first maturity occurring between 7.3 and $7.9 \mathrm{~cm}$, reached in six months. The species presented two spawning peaks along the year, and the artisanal fishery showed a higher pressure over the adult stock. The trophic spectrum was composed by 30 items, being Gammaridae, sand, other crustaceans and organic matter the basic elements of its diet. A mean value of 67.82 vessels operate yearly during eight months on the sea-bob-shrimp fishery at Armação do Itapocoroy, yielding a total of up to 170 ton/year.

KEY WORDS. Artisanal fishery, natural diet, population structure, seasonal fluctuations.
\end{abstract}

RESUMO. A pesca artesanal do camarão sete-barbas é denominada "pesca de sol a sol" e realizada em grande escala no litoral brasileiro, apresentando uma significativa importância econômica, histórica, social e cultural. Atualmente, a pesca desse camarão é considerada a de maior interesse econômico e o segundo recurso pesqueiro nas regiões Sudeste-Sul do Brasil. Com o objetivo de estudar a biologia e pesca do camarão sete-barbas na Armação do Itapocoroy, Penha ( $26^{\circ} 40^{\prime}-26^{\circ} 47^{\prime} \mathrm{S}$ e $\left.48^{\circ} 36^{\prime}-48^{\circ} 38^{\prime} \mathrm{W}\right)$, durante o período de agosto de 1996 a julho de 2003 foram realizadas coletas mensais com 30 minutos de duração. Foram registrados o número e a biomassa dos exemplares por arrasto, e entre anos de 1996-1997 e 1999-2001, também foram anotados o sexo, o comprimento e peso total, estádio de maturação. Além dessas informações, entre agosto de 1998 a julho de 1999 foi analisado a dieta natural da espécie. $X$. kroyeri (Heller, 1862) apresentou comprimento total variando entre 3,0 e $16,0 \mathrm{~cm}$ e flutuações sazonais na abundância e biomassa, com as maiores taxas de captura ocorreram durante os meses de verão e outono. A relação peso/comprimento indicou um padrão de crescimento tendendo ao isométrico com tamanho de primeira maturação entre 7,3 a $7,9 \mathrm{~cm}$, alcançados em seis meses de idade. A espécie apresentou dois picos de desova ao longo do ano, sendo que a pesca artesanal vem atuando com maior intensidade sobre o estoque adulto. $\mathrm{O}$ espectro trófico foi composto por 30 itens, sendo que os Gammaridae, areia, outros Crustacea e matéria orgânica os elementos básicos na dieta da espécie. Em média, 67,82 barcos atuam durante oito meses por ano na pesca do camarão sete-barbas na Armação do Itapocoroy, podendo capturar em torno de 170 toneladas/ano.

PALAVRAS CHAVE. Dieta natural, estrutura populacional, flutuações sazonais, pesca artesanal.

A pesca de camarões é realizada em grande escala no litoral brasileiro, apresentando uma significativa importância econômica, histórica, social e cultural. Essa atividade foi uma dentre os legados da cultura açoriana que contribuiu de maneira ex- pressiva para o desenvolvimento da pesca artesanal e industrial no litoral catarinense.

O camarão sete-barbas Xiphopenaeus kroyeri (Heller, 1862), apresenta ampla distribuição geográfica no Atlântico Ociden- 
tal, ocorrendo da Carolina do Norte (USA) a Santa Catarina (Brasil) (Holthuis 1980), e atualmente estendendo-se até o Rio Grande do Sul (D’InCão et al. 2002). Ao contrário dos camarões do gênero Penaeus, esta espécie não depende dos estuários para o desenvolvimento dos juvenis, onde a presença em zonas estuarinas está associada à penetração de cunha salina (HoLthuıs 1980, Paiva 1971, Williams 1965).

Aspectos biológicos e pesqueiro do camarão sete-barbas no litoral brasileiro recebeu atenção especial no Nordeste (MотAAlves \& Rodrigues 1977, Coelho \& Santos 1993, Santos \& Coelho 1996, Santos \& Ivo 2000), em São Paulo (Vieira 1947, Neiva \& Wise 1967, SANTOS et al. 1969, IWAi 1973, SEverino-Rodrigues et al. 1993, Nakagaki \& Negreiros-Fransozo 1998, Fransozo et al. 2000), no Paraná (Branco et al. 1994) e em Santa Catarina (Tremel 1968, Nascimento \& Poli 1986, Branco et al. 1999) contribuindo com informações relevantes para a espécie.

Xiphopenaeus kroyeri não apresenta estratificação populacional, sendo comum a ocorrência de juvenis e adultos na mesma área, onde a maturação gonadal ocorre ao longo do ano, sendo mais intensa no período de novembro a março (Vieira 1947, Neiva \& Wise 1967, Iwai 1973).

Nas regiões Sudeste e Sul X. kroyeri ocupa o $2^{\circ}$ lugar na produção comercial de camarão (IWAI 1973), participando com 50\% da captura total de camarões em 1984 e com 42\% em 1985 (SUDEPE-PDP 1987). Entretanto, a pesca de arrasto é considerada predatória e desestabilizadora das comunidades bentônicas, sendo freqüentemente realizada em criadouros de diversas espécies de interesse econômico (Branco \& Fracasso 2004).

Apesar dos trabalhos já realizados, o ciclo de vida de $X$. kroyeri ainda é pouco conhecido no litoral brasileiro, necessitando de novos estudos (VALENTINI et al. 1991). Assim, esse trabalho tem como objetivo acrescentar novas informações sobre aspectos da biologia e pesca do camarão sete-barbas na Armação do Itapocoroy, Penha, Santa Catarina, através de uma série temporal de dados.

\section{MATERIAL E MÉTODOS}

As coletas foram realizadas mensalmente na Armação do Itapocoroy, Penha, durante o período de julho 1996 a junho 2003, sendo uma coleta por mês, em três áreas tradicionais de atuação da pesca artesanal $\left(26^{\circ} 40^{\prime}-26^{\circ} 47^{\prime} \mathrm{S}\right.$ e $\left.48^{\circ} 36^{\prime}-48^{\circ} 38^{\prime} \mathrm{W}\right)$ : Ponta da Vigia, Ilha Feia e Ilhas Itacolomis com duração de uma hora. Foram utilizadas duas redes-de-arrastos com portas (doublé rigged), malha de 3,0 cm na manga e corpo e de 2,0 $\mathrm{cm}$ no ensacador, tracionada por baleeira com velocidade média de 2,0 nós (Branco et al. 2002).

Os camarões capturados foram etiquetados e acondicionados em saco plástico e mantidos em caixa de isopor com gelo. Após a coleta, os exemplares que não puderam ser processados foram mantidos em "freezer" até serem trabalhados.

A pesca artesanal do camarão sete-barbas é denominada "pesca de sol a sol", com início das atividades ao amanhecer e encerramento antes do por do sol (Branco et al. 2001). Assim, a cada coleta foram registradas, às 18:00 horas, o número de barcos ancorados que atuam nessa atividade de pesca. O número médio, em conjunto com a média dos dias de pesca e os dados obtidos no barco das coletas, foram utilizados como parâmetro para estimar a produção de camarão na Armação do Itapocoroy.

No laboratório, de cada exemplar capturado entre o $1^{\circ}$ ano (agosto/1996 a julho/1997), o $2^{\circ}$ (agosto/1999 a julho/2000) e o $3^{\circ}$ ano (agosto/2000 a julho/2001), foram registrados o sexo, estádio de maturação (Pérez Farfante 1970), comprimento total (Lt) em cm e o peso total (Wt) em gramas. Das fêmeas adultas nos dois primeiros anos, foram retirados os ovários e registrado o seu peso $(\mathrm{Wg})$ para determinar a época de reprodução.

O teste do $\chi^{2}$, ao nível de significância de 5\% e n-1 graus de liberdade $(n=2)$, foi aplicado para verificar a possível diferença entre a proporção sexual, mensalmente e por classes de comprimento total (VAzzoler 1996).

A relação peso total/comprimento total foi estimada para machos e fêmeas através da equação (SANTOS 1978):

$\mathrm{Wt}=\mathrm{a} \mathrm{Lt} t^{\mathrm{b}}$, onde: (a) fator de condição e (b) constante da relação peso/comprimento.

O índice gonadassomático (IGS) foi obtido através da expressão (VAzzoler 1996): IGS = Wg/Wt.100, onde: $(\mathrm{Wg}$ ) peso das gônadas e (Wt) peso total. Em seguida foram estimados os valores médios mensais desse índice.

$\mathrm{O}$ tamanho da primeira maturação gonadal $\left(\mathrm{Lt}_{\mathrm{PM}}\right)$, que corresponde ao comprimento onde $50 \%$ dos exemplares são adultos, foi estimado graficamente para machos e fêmeas conforme VAzzoler (1981). Para verificar a atuação da pesca artesanal sobre os camarões jovens e adultos, utilizou-se a distribuição de freqüência por classe de comprimento de machos e fêmeas, baseando-se na estimativa do tamanho de primeira maturação gonadal (BRANCo et al. 1999).

A curva de crescimento em comprimento total foi estabelecida pelo método da distribuição de freqüência para sexos separados (SAntos 1978), sendo a expressão de von Bertalanffy (BERTALANFFy 1938) aplicada para o camarão setebarbas: $\mathrm{Lt}=\mathrm{L}_{\infty}\left[1-\mathrm{e}^{-\mathrm{k}(\mathrm{t}-\mathrm{t} 0)}\right]$, onde: $(\mathrm{Lt})$ comprimento total na idade $t,\left(\mathrm{~L}_{\infty}\right)$ comprimento assintótico, (e) base dos logaritmos neperianos, $(\mathrm{K})$ constante relacionada com a taxa de crescimento, $\left(\mathrm{t}_{0}\right)$ parâmetro relacionado com o comprimento ao nascer e (t) idade considerada.

A validade da expressão de von Bertalanffy foi testada, previamente, com a aplicação da transformação de FordWalford (WALFORD 1946) e os parâmetros estimados conforme SANTOS (1978). Para X. kroyeri, cujo comprimento total ao nascer é desprezível, assume-se que $t_{0}$ seja igual a zero.

A curva de crescimento em peso foi obtida pelo método dedutivo (SANTOS 1978), após o conhecimento da relação peso/ comprimento total para machos e fêmeas, resultando na expressão: $\mathrm{Wt}=\mathrm{W}_{\infty}\left[1-\mathrm{e}^{-\mathrm{k}(\mathrm{t}-\mathrm{t} 0)}\right]^{\mathrm{b}}$, onde: $(\mathrm{Wt})$ peso na idade $\mathrm{t},\left(\mathrm{W}_{\infty}\right)$ peso assintótico e (b) constante relacionada com o crescimento da espécie, estimada na relação peso/comprimento total.

A média mensal da CPUE $(\mathrm{kg} / \mathrm{h})$ e número de exemplares 


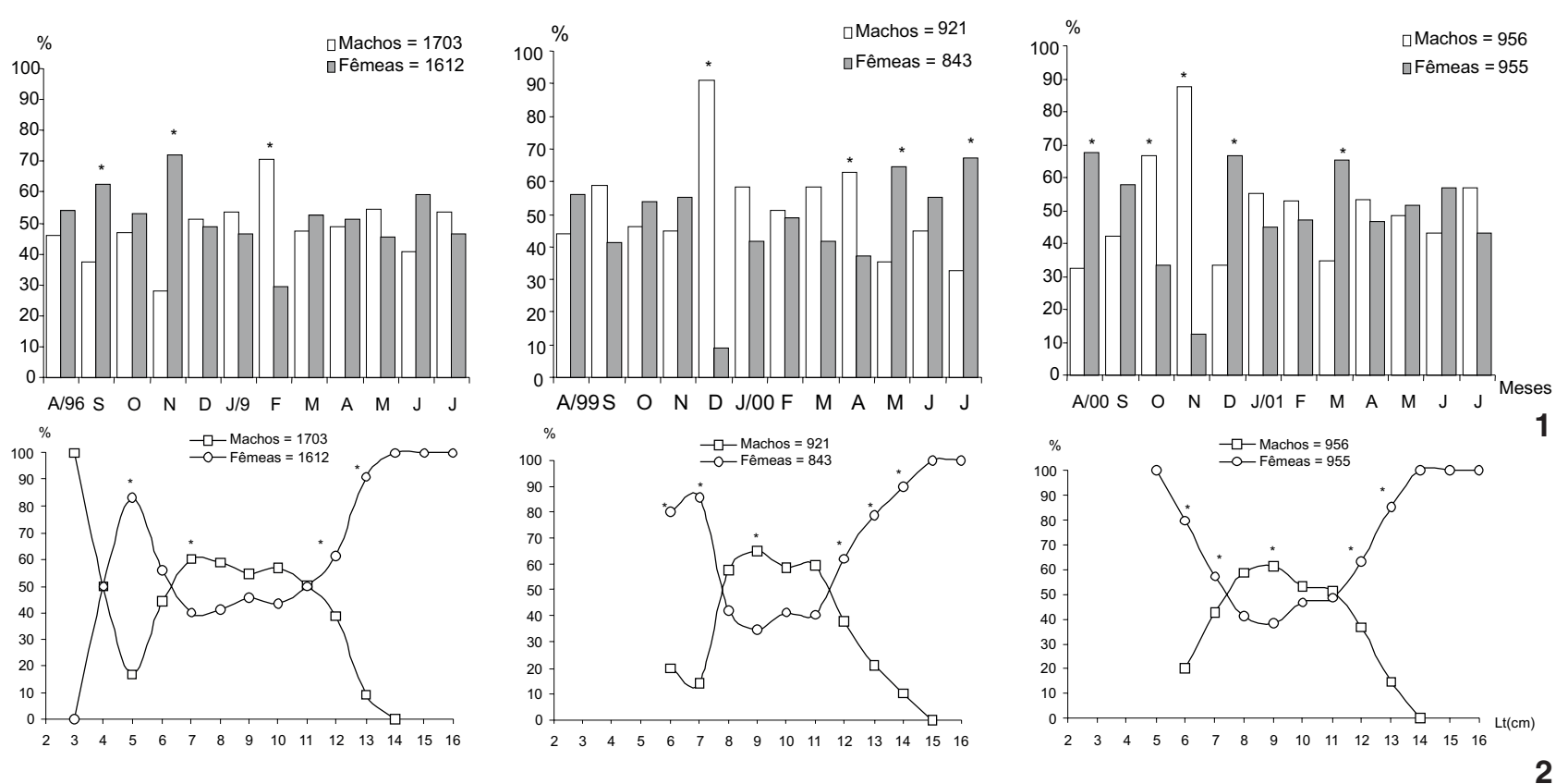

Figuras 1-2. Distribuição mensal da (1) freqüência de ocorrência e (2) percentual por classe de comprimento total (\%) de machos e fêmeas de $X$. kroyeri, nos anos de 1996-1997, 1999-2000, 2000-2001. * = diferença significativa, $\chi^{2}(p<0,05)$.

entre julho/1996 a junho/2003, foi obtida com as informações das três áreas de coleta. A ANOVA (SoKAL \& RoHLF 1969) foi utilizada para verificar a existência de diferenças significativas nas CPUE de $X$. kroyeri, por ano e sazonal. O contraste das médias, através do teste Tuckey-Kramer, foi aplicado na ocorrência de diferenças significativas para indicar a fonte causadora das variações. O teste " $\mathrm{t}$ " de Student $(\mathrm{p}<0,05)$ foi utilizado para verificar a existência de diferenças significativas entre os valores de "b" da relação peso/comprimento.

No período de agosto/1998 a julho/1999, além das informações de CPUE e do número de exemplares acima mencionadas, são sumarizados nesse trabalho, os resultados obtidos por Branco \& Moritz Jr. (2001) sobre a dieta natural de 407 exemplares de $X$. kroyeri. Esses dados, reunidos aos aqui apresentados, complementarão as informações básicas sobre a biologia da espécie na área de estudo, sendo pela primeira vez disponibilizados na literatura científica nacional de forma integrada.

\section{RESULTADOS}

\section{Proporção sexual}

Para o total de $X$. kroyeri capturado nos três anos, as freqüências percentuais de machos e fêmeas foram muito próximas, $51,37 \%$ e $48,63 \% ; 52,21 \%$ e $47,78 \% ; 50,02 \%$ e $49,97 \%$ respectivamente, não diferindo do esperado de 1:1 (Fig. 1). Esta tendência não foi mantida ao analisar as freqüências mensais através do $\chi^{2}$, indicando diferenças significativas $(\mathrm{p}<0,05)$ no $1^{\circ}$ ano a favor das fêmeas nos meses de setembro e novembro/1996 e dos machos em fevereiro/1997, no $2^{\circ}$ ano as fêmeas dominaram nas amostragens de maio e julho/2000 e os machos em dezembro/1999 e abril/2000, no $3^{\circ}$ ano o predomínio das fêmeas ocorreu entre agosto-dezembro/2000 e maio/2001 e os machos em outubro-novembro/2000 (Fig. 1). Nos demais meses, foi observado um equilíbrio na proporção sexual da população.

As distribuições de freqüências relativas por classes de comprimento total, mostram que ocorreram camarões numa amplitude de variação entre 3,0 a 14,0 cm (machos) e entre 4,0 a 16,0 cm (fêmeas) (Fig. 2). Os machos predominaram significativamente, de acordo com o $\chi^{2}$, nas classes de 7,0 e 9,0 cm e as fêmeas nas classes entre 5,0 a 7,0 e 12,0 a 13,0 cm (Fig. 2).

\section{Estrutura sazonal de comprimentos}

A figura 3 mostra, sazonalmente, a distribuição de freqüência das classes de comprimento total de machos e fêmeas, nos três anos de coleta. Durante os meses de primavera foram registradas as menores freqüências de captura e a ocorrência, principalmente de camarões adultos, entre as classes de 7,0 a $15,0 \mathrm{~cm}$, enquanto que no verão ocorreu um incremento na população com a participação dos juvenis, atingindo as maiores abundâncias no outono, seguido da redução na abundância de camarões durante os meses de inverno (Fig. 3). A estrutura sazonal de comprimento da população apresentou componentes unimodais na maioria das estações, com as classes modais oscilando entre 7,0 a $12,0 \mathrm{~cm}$ de comprimento total, sendo comum a ocorrência de camarões juvenis e adultos entre os meses de verão, outono e inverno (Fig. 3). 
$1996-1997$
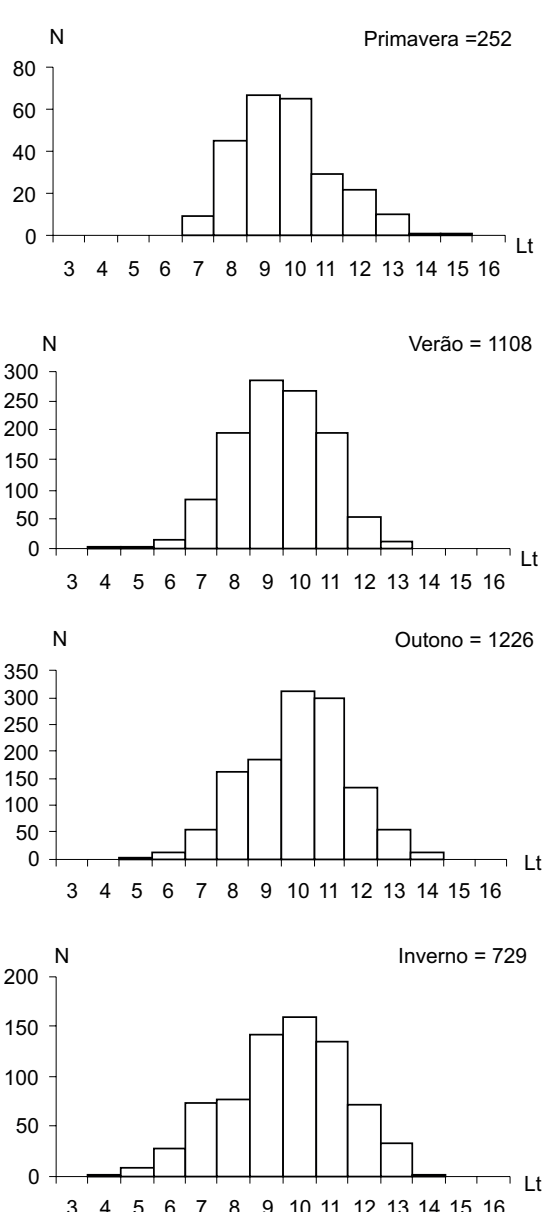

$1999-2000$
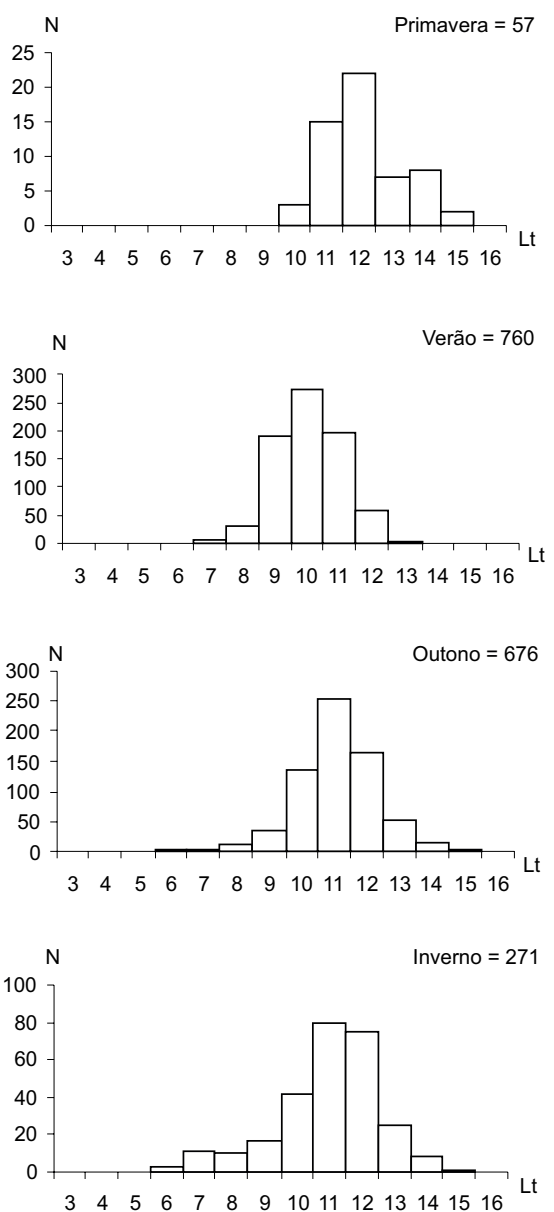
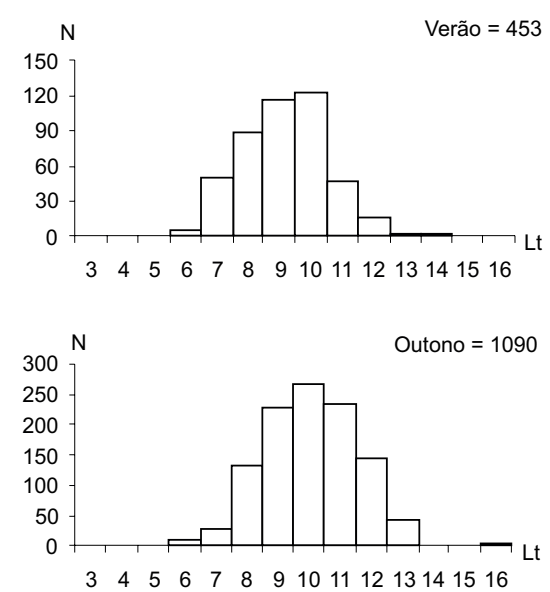

$2000-2001$
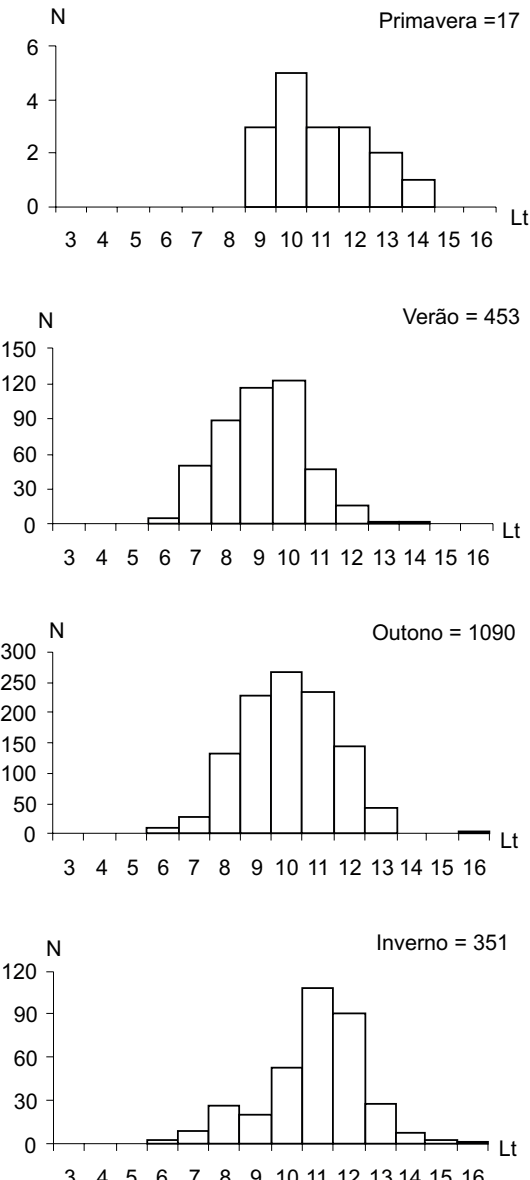

Figura 3. Distribuição sazonal das freqüências de comprimento total de X. kroyeri, durante os anos de 1996-1997, 1999-2000, $2000-2001$.

\section{Relação peso/comprimento}

Os valores do peso total foram lançados em gráficos em função dos valores do comprimento total, para os sexos separados, indicando uma boa aderência entre as variáveis, o que foi corroborado pelos valores do coeficiente de determinação $\left(\mathrm{r}^{2}\right)$ (Tab. I), com crescimento isométrico ou tendendo a esse e valores estatisticamente iguais entre os anos ou sexo (teste $t, p$ $<0,05$ ), exceto nos machos capturados em 2000-2001 que foi alométrico negativo.

A amplitude de variação do comprimento nos machos foi de 3,0 a $13,0 \mathrm{~cm}$ e a do peso de 0,48 a $12,86 \mathrm{~g}$, enquanto que nas fêmeas, variou entre 4,0 a $16,0 \mathrm{~cm}$ e 0,45 a $18,35 \mathrm{~g}$.

\section{Relação comprimento da carapaça/ comprimento total}

A relação comprimento da carapaça / comprimento total foi determinada para machos e fêmeas. A existência de relação linear pela origem é demonstrada nas expressões: Machos $\mathrm{Lc}=0,1941 \mathrm{Lt}, \mathrm{r}=0,9481$; Fêmeas $\mathrm{Lc}=0,2021 \mathrm{Lt}, \mathrm{r}=0,9534$.

Essas expressões representam o crescimento relativo entre
Tabela I. Equações da relação peso total/comprimento total com os valores do teste $t(p<0,05)$ para machos e fêmeas de $X$. kroyeri, na Armação do Itapocoroy, Penha, Santa Catarina.

\begin{tabular}{|c|c|c|}
\hline Machos & Fêmeas & Teste $\mathrm{t}$ \\
\hline 1996-1997 Wt $=0,0055 \mathrm{Lt}^{3,0039}$ & $W t=0,0063 \mathrm{Lt}^{2,9536}$ & $t=0,025$ \\
\hline$r^{2}=0,9514$ & $r^{2}=0,9482$ & $\mathrm{n}=3313$ \\
\hline $1999-2000 \mathrm{Wt}=0,0058 \mathrm{Lt}^{2,9362}$ & $\mathrm{Wt}=0,0047 \mathrm{Lt}^{3,0330}$ & $t=0,037$ \\
\hline$r^{2}=0,8598$ & $r^{2}=0,9125$ & $\mathrm{n}=1762$ \\
\hline $2000-2001 \mathrm{Wt}=0,0089 \mathrm{Lt}^{2,7566}$ & $\mathrm{Wt}=0,0063 \mathrm{Lt}^{2,9062}$ & $t=2,567^{*}$ \\
\hline$r^{2}=0,9038$ & $r^{2}=0,9384$ & $\mathrm{n}=1909$ \\
\hline
\end{tabular}

$\left(^{*}\right)$ Significativo para $\mathrm{p}<0,05$.

Lc e Lt e a constante de regressão (coeficiente angular da reta) corresponde a um índice biométrico obtido para a espécie.

\section{Crescimento}

As expressões matemáticas das curvas de crescimento em comprimento total (Figs 4 e 5) são descritas pelas equações: 


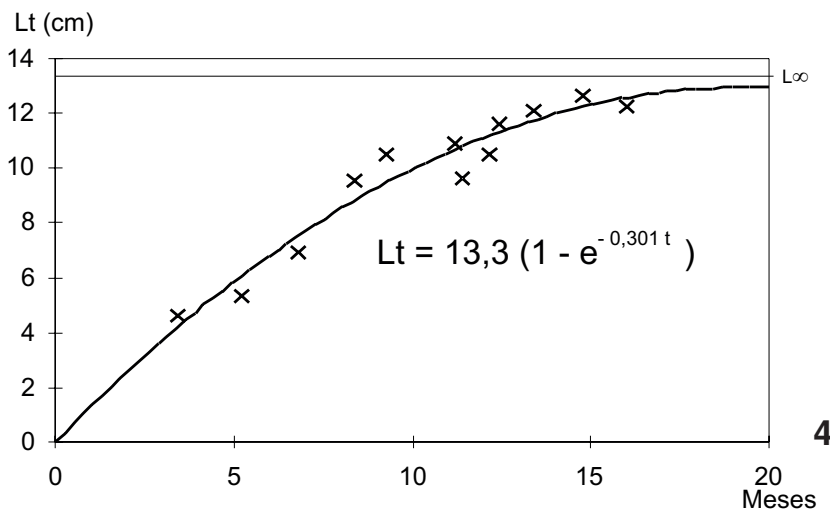

Figuras 4-5. Curva de crescimento em comprimento total para machos

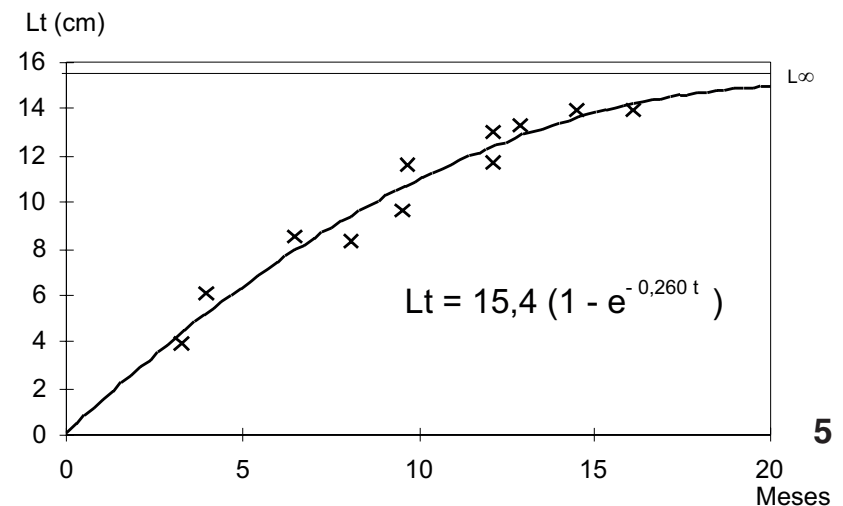

(4) e fêmeas (5) de X. kroyeri, durante o ano de 1996-1997.
Machos Lt = 13,3 $\left(1-\mathrm{e}^{-0,301 t}\right)$; Fêmeas Lt = 15,4 $\left(1-\mathrm{e}^{-0,260 t}\right)$.

Xiphopenaeus kroyeri apresenta uma constante catabólica elevada, sendo que o maior valor de comprimento total médio observado na população da Armação do Itapocoroy é atingindo em torno dos 17 meses de idade.

O crescimento em comprimento da carapaça $(\mathrm{cm})$, estimado a partir das relações entre os índices biométricos e os valores de $\mathrm{L}_{\infty}$ das equações de crescimento em comprimento total, resultaram nas seguintes expressões:

Machos Lc = 2,56 (1 - $\left.\mathrm{e}^{-0,301 t}\right)$; Fêmeas Lc = 3,11 $\left(1-\mathrm{e}^{-0,260 t}\right)$.

$\mathrm{O}$ crescimento em peso de $X$. kroyeri pode ser expresso: Machos Wt $=12,7\left(1-\mathrm{e}^{-0,301 t}\right)^{3,0039}$; Fêmeas Wt $=20,2\left(1-\mathrm{e}^{-0,260 t}\right)^{2,9536}$

Os machos atingem, em média, menor peso que as fêmeas para uma mesma classe de comprimento.

\section{Tamanho de primeira maturação}

$\mathrm{O}$ tamanho de primeira maturação $\left(\mathrm{Lt}_{\mathrm{PM}}\right)$ foi estimado em 7,3 cm para os machos e 7,9 cm para as fêmeas (Fig. 6). A partir do comprimento total de $12,0 \mathrm{~cm}$, todos os camarões coletados eram adultos.

Analisando-se as distribuições anuais das freqüências de comprimento total (Fig. 7), considerando-se simultaneamente os valores estimados para machos e fêmeas do tamanho de primeira maturação, verifica-se que o esforço da pesca artesanal na Armação do Itapocoroy está basicamente concentrado sobre o estoque adulto (machos $=75,7 \%$ e fêmeas $=63,4 \%$ ), e com menor intensidade sobre os juvenis (machos $=24,3 \% \mathrm{e}$ fêmeas $=36,6 \%$ ).

\section{Aspectos reprodutivos}

A curva de maturação obtida através dos valores médios mensais do IGS (Fig. 8) sugere que $X$. kroyeri apresenta um período reprodutivo longo com dois picos de desova: $O$ primeiro e mais intenso, ocorreu no final da primavera (dezembro/96), o segundo, embora menos acentuado, ocorreu durante o outono (maio/97). Esse padrão manteve-se praticamente inalterado em 2000-2001, com um pequeno incremento na atividade reprodutiva no final do outono, a partir de abril até junho de 2001 (Fig. 8).

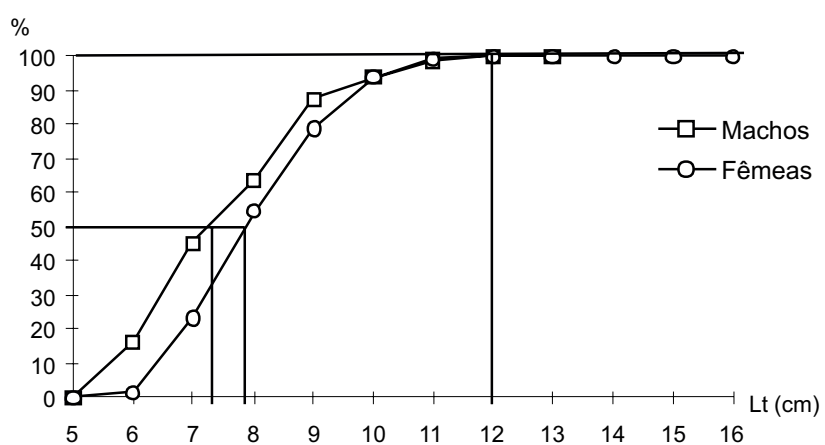

Figura 6. Distribuição de freqüências acumuladas de machos e fêmeas, por classe de comprimento total entre agosto/1996 a juIho/1997. Machos - Lt ${ }_{P M}=7,3 \mathrm{~cm}$; Fêmeas $-\mathrm{Lt}_{\mathrm{PM}}=7,9 \mathrm{~cm}$.

\section{Alimentação natural}

Foram analisados 407 estômagos de Xiphopenaeus kroyeri, sendo 194 de machos, dos quais 5,15\% estavam vazios e $94,85 \%$ continham alimento; dos 213 estômagos retirados das fêmeas, $3,76 \%$ apresentaram-se vazios e $96,24 \%$ com alimento.

Através da análise do conteúdo estomacal dos exemplares foi possível identificar 30 itens componentes da dieta natural do camarão sete-barbas (Tab. II). Os itens mais importantes foram Gammaridae, matéria orgânica não identificada, Acetes americanus Ortmann, 1893, Polychaeta, Globigerina, Gastropoda e Osteichthyes. Os menos freqüentes foram Bivalvia, Bryozoa, Cumacea, Isopoda, Macrófitas, Ostracoda e Hydrozoa (Tab. II).

A figura 9 apresenta a contribuição em freqüência de ocorrência, pontos e o índice alimentar, durante o período de agosto/98 a julho/99. Embora o item areia faça parte dessa relação, persistem dúvidas se a ingestão é proposital ou acidental. Esse componente foi o mais freqüente na dieta de X. kroyeri, enquanto que, Gammaridae, outros Crustacea, MOND e Polychaeta dominaram em pontos. De acordo com o IAi, os Gammaridae $(0,496)$, areia $(0,150)$, Crustacea $(0,119)$ e MOND $(0,117)$ 


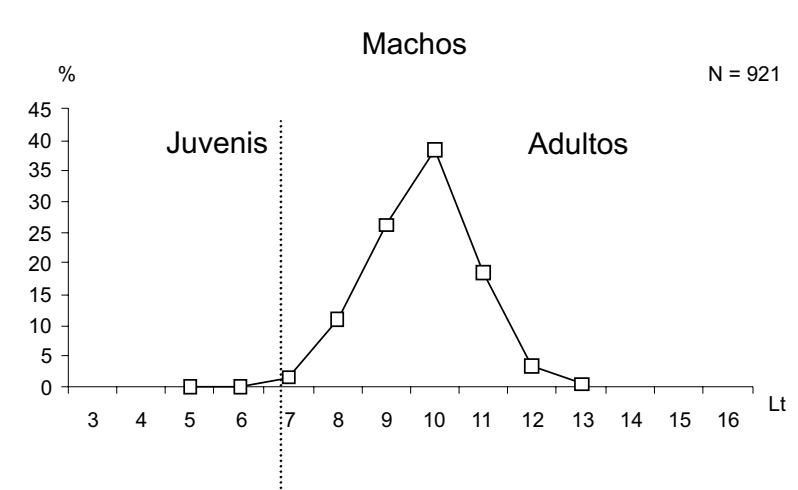

$1996-1997$
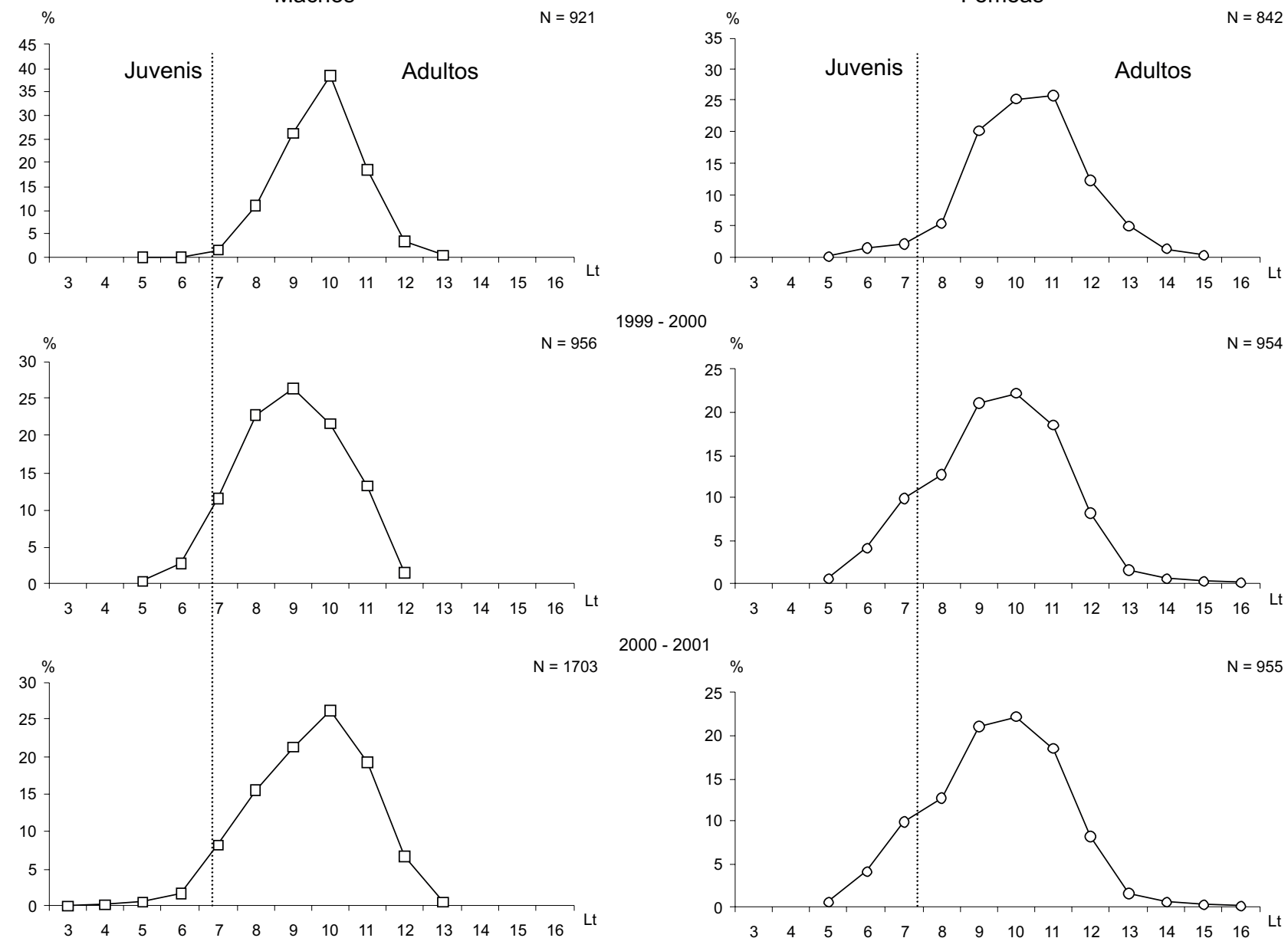

Figura 7. Distribuição de freqüências de comprimento total, por sexo de X. kroyeri (juvenis e adultos), durante os anos de 1996-1997, 1999-2000, 2000-2001.

formam o principal grupo de presas, seguidos dos Foraminiferida $(0,037)$, Polychaeta $(0,036)$ e Osteichthyes $(0,011)$, e Mollusca (0,019), algas (0,009), Echinodermata $(0,002)$. Macrófitas, Hydrozoa, Bryozoa, podem ser considerados de ocorrência acidental na dieta da espécie (Fig. 9).

\section{Captura por Unidade de esforço}

De acordo com a figura 10 as maiores taxas médias mensais em CPUE e número de camarão sete-barbas, capturados nos sete anos consecutivos de coleta na Armação do Itapocoroy, ocorreram entre os meses de janeiro a julho, com picos anuais alternando-se, principalmente entre abril-maio. Não foram observadas diferenças significativas entre as CPUE $\left(\mathrm{F}_{6-77}=1,528\right.$; $\mathrm{p}<0,05)$, número de exemplares $\left(\mathrm{F}_{6-77}=1,507 ; \mathrm{p}<0,05\right)$ e os anos de coleta. Entretanto, quando analisados os dados por estação do ano, fica evidente as flutuações sazonais que o estoque de camarão sete-barbas está submetido ao longo de um ciclo anual, com diferenças significativas $\left(\mathrm{F}_{3-80}=21,518 ; \mathrm{p}<\right.$
$0,001)$ e $\left(\mathrm{F}_{3-80}=20,483 ; \mathrm{p}<0,001\right)$, respectivamente, entre as estações do ano e as médias das CPUE e o número de exemplares (Fig. 10). As diferenças ocorreram, principalmente, nas estações de verão e outono, onde foram registradas as maiores taxas médias de captura.

\section{Estimativa da captura total}

O número de embarcações direcionadas à pesca de camarão na Armação do Itapocoroy apresentou pequenas oscilações ao longo dos sete anos, com uma média de 67,82 barcos em atividade de pesca e 11,49 em reparo (Fig. 11). Essas variações, no contingente de embarcações, podem ser atribuídas, principalmente, a sazonalidade da espécie-alvo e ao reparo das embarcações danificadas durante o processo de pesca. Os dados de captura do camarão sete-barbas oriundos da embarcação utilizada nos sete anos consecutivos de coleta, foram considerados representativos para a frota artesanal da Armação do Itapocoroy e adotados como um estimador satisfatório dessa 

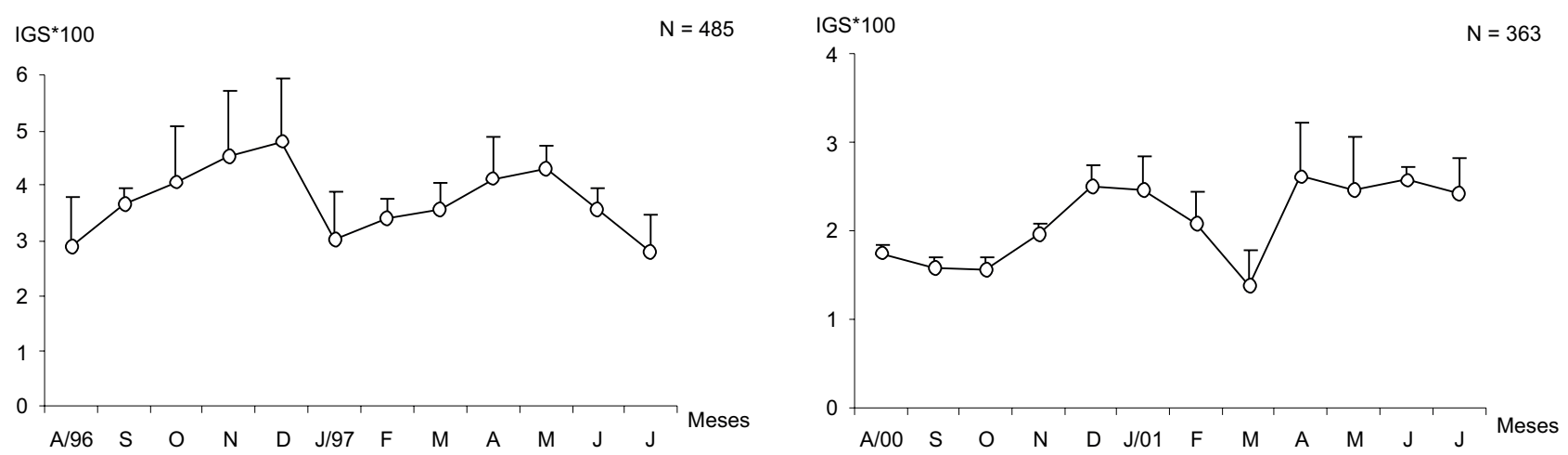

Figura 8. Variação mensal do IGS das fêmeas de X. kroyeri, durante os anos de 1996-1997 e 2000-2001. As barras verticais correspondem ao erro da média.

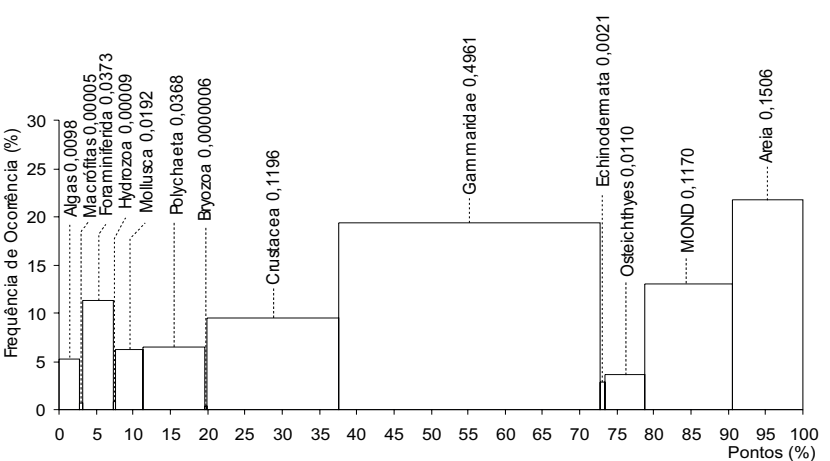

Figura 9. Freqüência de ocorrência (\%) e de pontos (\%) dos grupos alimentares e seus respectivos índices alimentares de $X$. kroyeri, durante o período de coleta. Fonte: Branco \& Moritz JR. (2001).

modalidade de pesca. Os valores médios de CPUE dos arrastos, com duração padrão de uma hora, foram multiplicados por seis, o que corresponde à média de seis lances diários de pesca. Dessa forma, com esforço diário médio de 67,8 barcos (Fig. 11) e CPUE médio padrão de 1,34 kg/barco (Fig. 10), obter-se-ia uma captura média diária de $545,11 \mathrm{~kg}$, que multiplicada por 240 dias de pesca, resultaria em uma produção de aproximadamente 130,82 toneladas/ano de camarão sete-barbas.

\section{DISCUSSÃO}

A literatura disponível sobre proporção sexual de camarão sete-barbas é restrita. CoelHo \& SANTOS (1993), analisando a proporção média anual de $X$. kroyeri nos desembarques na região de Tamandaré, PE, constataram que a população manteve o equilíbrio de 1:1, embora com abundância média das fêmeas relativamente superior a dos machos. Padrão semelhante foi registrado por SEVERINO-RodRigues et al. (1993), na pesca artesanal de camarões sete-barbas no litoral de São Paulo ocorrendo um equilíbrio na proporção sexual na categoria camarão "bruto" e nas áreas de pesca.
Tabela II. Freqüência de ocorrência (FO) e de pontos (MP) dos itens alimentares no conteúdo estomacal de $X$. kroyeri durante o período de agosto/98 a julho/99. (MOND) matéria orgânica não determinada.

\begin{tabular}{|c|c|c|c|c|}
\hline Itens & FO & $\%$ & MP & $\%$ \\
\hline Diatomaceas & 14 & 1,04 & 37 & 0,14 \\
\hline Algas & 54 & 4,02 & 668 & 2,51 \\
\hline Macrófitas & 4 & 0,30 & 70 & 0,26 \\
\hline Foraminiferida & 22 & 1,64 & 58 & 0,22 \\
\hline Globigerina & 124 & 9,24 & 1055 & 3,97 \\
\hline Elphidium & 11 & 0,82 & 51 & 0,19 \\
\hline Hydrozoa & 6 & 0,45 & 74 & 0,28 \\
\hline Mollusca & 9 & 0,67 & 58 & 0,22 \\
\hline Gastropoda & 63 & 4,69 & 835 & 3,14 \\
\hline Bivalvia & 1 & 0,07 & 20 & 0,08 \\
\hline Cephalopoda & 4 & 0,30 & 79 & 0,30 \\
\hline Lolliguncula brevis & 9 & 0,67 & 179 & 0,67 \\
\hline Polychaeta & 75 & 5,59 & 1844 & 6,93 \\
\hline Nereidae & 12 & 0,89 & 225 & 0,85 \\
\hline Bryozoa & 1 & 0,07 & 3 & 0,01 \\
\hline Crustacea & 10 & 0,75 & 227 & 0,85 \\
\hline Ostracoda & 2 & 0,15 & 4 & 0,02 \\
\hline Copepoda & 9 & 0,67 & 175 & 0,66 \\
\hline Dendrobranchiata & 17 & 1,27 & 570 & 2,14 \\
\hline Acetes americanus & 49 & 3,65 & 2425 & 9,12 \\
\hline Brachyura & 24 & 1,79 & 735 & 2,76 \\
\hline Ovos de Crustacea & 3 & 0,22 & 83 & 0,31 \\
\hline Mysidacea & 6 & 0,45 & 487 & 1,83 \\
\hline Cumacea & 1 & 0,07 & 20 & 0,08 \\
\hline Isopoda & 2 & 0,15 & 30 & 0,11 \\
\hline Gammaridae & 259 & 19,30 & 9367 & 35,22 \\
\hline Ophiuroidea & 35 & 2,61 & 295 & 1,11 \\
\hline Osteichthyes & 49 & 3,65 & 1103 & 4,15 \\
\hline MOND & 173 & 12,89 & 3310 & 12,45 \\
\hline Areia & 294 & 21,91 & 2506 & 9,42 \\
\hline Total & 1342 & 100,00 & 26593 & 100,00 \\
\hline
\end{tabular}

Fonte: Branco \& Moritz Jr. 2001. 

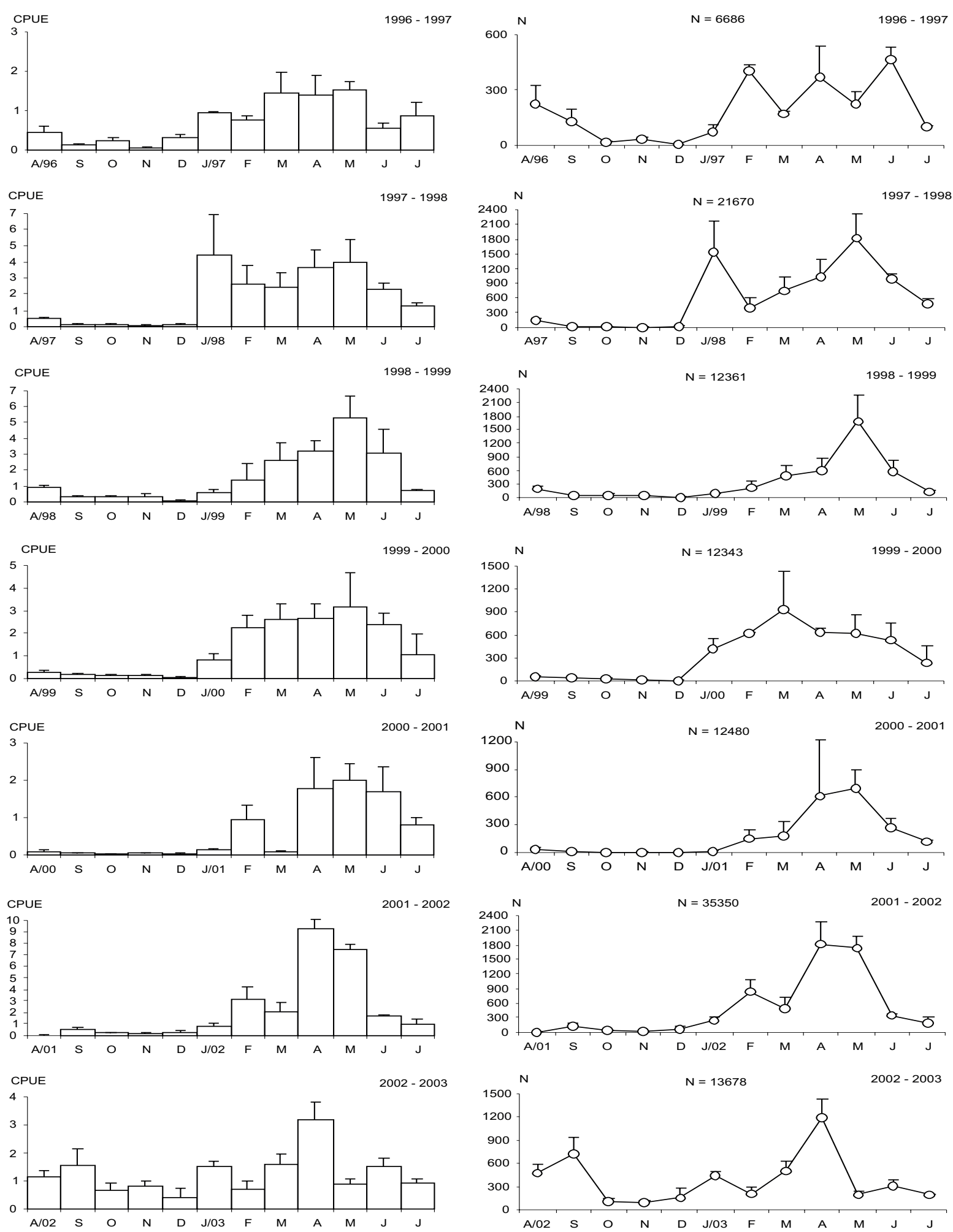

Figura 10. Variação média mensal da CPUE (Kg/h) e do número de X. kroyeri, durante o período de 1996 a 2003. As barras verticais correspondem ao erro da média. 


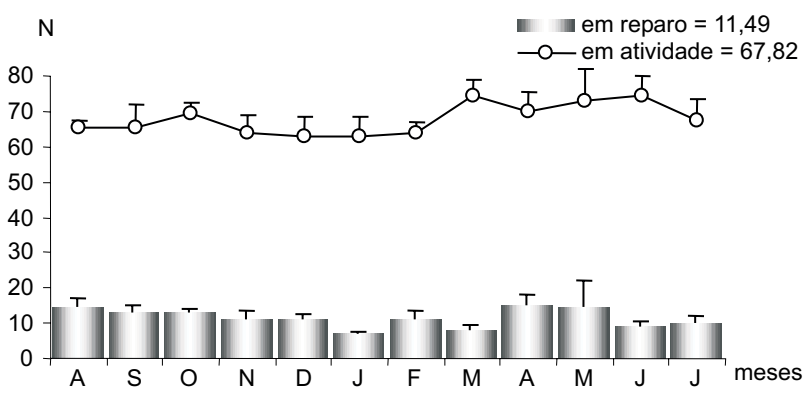

Figura 11. Número médio de embarcações em atividade e reparo, na Armação do Itapocoroy, direcionadas a pesca do camarão setebarbas, durante o período de 1996 a 2003. As barras verticais correspondem ao erro da média.

Na Armação do Itapocoroy, essa tendência foi mantida quando considerado o total de exemplares capturados nos três anos de coleta. Entretanto, quando analisada mensalmente, constatou-se disparidade entre os sexos, bem como em relação ao tamanho. Essas flutuações na proporção sexual dos camarões, podem ser atribuídas, em parte, a distribuição segregada dos sexos em alguns meses do ano.

De acordo com Pérez Farfante (1978), o comprimento total máximo registrado para $X$. kroyeri, ao longo da sua área de distribuição geográfica foi de $11,5 \mathrm{~cm}$ para os machos e $14,0 \mathrm{~cm}$ para as fêmeas. Nascimento \& Poli (1986) trabalhando na Baía de Tijucas, Santa Catarina, obtiveram para a espécie um comprimento total máximo de $15,0 \mathrm{~cm}$. Na população da Armação do Itapocoroy, os resultados obtidos elevam o tamanho da espécie para 13,0 cm nos machos e $16,0 \mathrm{~cm}$ nas fêmeas. Essas variações, provavelmente estão associadas à distribuição geográfica, crescimento diferenciado das populações, exploração pesqueira e a disponibilidade de alimento.

As informações disponíveis sobre o ciclo de vida de $X$. kroyeri, indicam que não existem migrações de recrutamento ao estoque adulto, possibilitando a ocorrência de juvenis e adultos na mesma área de coleta (VIeIRA 1947, IwaI 1973).

Padrão semelhante foi observado neste estudo, demonstrando que a estrutura sazonal de comprimentos da população é mantida em função dos eventos do ciclo de vida da espécie. Os histogramas das distribuições das classes de comprimento mos- tram que, indivíduos adultos predominam sobre os juvenis, contrariando o registrado para a espécie na região de Caravelas (Bahia) (SANTOS \& Ivo 2000) e na maioria das populações naturais.

A relação peso/comprimento tem sido utilizada para facilitar a estimativa do peso de um exemplar, através do conhecimento do seu comprimento e determinar o tipo de crescimento das espécies, sendo amplamente empregada em estudos de dinâmica populacional e avaliação de estoques (BRANCO et al. 2002). Em geral, os camarões Penaeidae apresentam uma tendência de crescimento alométrico diferenciado entre os sexos. Esse padrão foi observado nas seguintes populações de camarões: Artemesia longinaris Bate, 1888 de Mar del Plata (Boschi 1969), Farfantepenaeus paulensis Pérez Farfante,1967 capturados em mar aberto e desembarcados em Santos, São Paulo, (Mello 1973), ou para camarões dessa espécie, distribuídos ao longo da costa Sudeste e Sul do Brasil (Zenker \& Agnes 1977), para X. kroyeri no litoral de São Paulo (SEverino-Rodrigues et al. 1993) e na Foz do Rio Itajaí-Açú, Santa Catarina (Branco et al. 1999). O padrão alométrico não foi mantido na população da Armação do Itapocoroy, onde predominou o crescimento isométrico ou tendendo a esse, exceto nos machos capturados em 2000-2001 que foi alométrico.

Nos crustáceos não existe uma estrutura dura que permita determinar marcos de idade como ocorre em outros animais. Assim, o método da distribuição de freqüência de comprimento total é o mais acessível para o estudo do crescimento de X. kroyeri. Essa metodologia vem sendo adotada por vários autores na determinação das curvas de crescimento dos camarões Penaeidae (Branco et al. 1999, Villela et al. 1997, Branco et al. 1994, NASCIMENTo \& Poli 1986, D'INCão 1984, Mello 1973, SANTos et al. 1969).

Em geral, nos camarões Penaeidae, os machos apresentam constante de crescimento $(\mathrm{K})$ mais elevada que as fêmeas e comprimentos assintóticos menores (GARCIA \& Le Reste 1981). Padrão semelhante de crescimento foram registrados nas populações de $X$. kroyeri da região Sudeste-Sul do Brasil, onde o comprimento médio máximo calculado oscila entre 12,2 a 16,2 cm e a constante catabólica entre 0,226 a 0,615 (Tab. III).

O índice biométrico obtido através da relação comprimento da carapaça/comprimento total, permite, na prática, estimar o valor de uma variável através do conhecimento da outra. Para determinado comprimento total, corresponderá um comprimen-

Tabela III. Comprimento médio máximo e constante catabólica para machos e fêmeas de $X$. kroyeri da região Sudeste-Sul do Brasil.

\begin{tabular}{|c|c|c|c|c|c|}
\hline \multirow{2}{*}{ Localidade } & \multirow{2}{*}{ Autores } & \multicolumn{2}{|c|}{ Machos } & \multicolumn{2}{|c|}{ Fêmeas } \\
\hline & & $L \infty$ & K & $L \infty$ & K \\
\hline Baía de Santos, São Paulo & SANTOs et al. (1969) & 14,4 & 0,374 & 16,2 & 0,329 \\
\hline *Baía de Tijucas, Santa Catarina & Nascimento \& Poli (1986) & 16,0 & 0,226 & - & - \\
\hline Praia de Matinhos, Paraná & Branco et al. (1994) & 13,5 & 0,615 & 15,0 & 0,531 \\
\hline Foz do Rio Itajaí-açú, Santa Catarina & Branco et al. (1999) & 12,2 & 0,235 & 14,1 & 0,279 \\
\hline Armação do Itapocoroy, Santa Catarina & Presente estudo & 13,2 & 0,301 & 15,4 & 0,260 \\
\hline
\end{tabular}

$\left(^{*}\right)$ Sexos grupados

Revista Brasileira de Zoologia 22 (4): 1050-1062, dezembro 2005 
to de carapaça, geralmente maior nas fêmeas que nos machos (BRANCo et al. 1999). A praticidade do índice foi constatada na obtenção das curvas em crescimento da carapaça de $X$. kroyeri.

De acordo com BRANCo et al. (1994), as curvas de crescimento em peso de $X$. kroyeri sugerem que os machos crescem mais rapidamente que as fêmeas, atingindo em média, peso inferior para a mesma classe de comprimento. Comportamento semelhante foi observado nesse estudo, onde os pesos máximos registrados para a espécie, estiveram muito próximos dos pesos assintóticos estimados.

NAScimento \& Poli (1986) indicam ausência de dimorfismo sexual quanto ao comprimento total de $X$. kroyeri na Baía de Tijucas, Santa Catarina. Entretanto, quando comparamos os comprimentos e pesos assintóticos com a população da Armação do Itapocoroy, torna-se evidente a existência de dimorfismo sexual e o emprego de equações distintas de crescimento para a espécie.

Os camarões do gênero Penaeus apresentam um ciclo de vida relativamente curto, variando entre 16 a 50 meses. Esse padrão segue a tendência registrada para $X$. kroyeri, onde o comprimento máximo obtido na população, pode ser atingido em cerca de 17 meses de idade.

O conhecimento do tamanho de primeira maturação gonadal é fundamental para a administração racional dos estoques de camarões, pois fornece a informação básica para a determinação do tamanho mínimo de captura e dimensionamento das malhas das redes. Além disso, a sobreposição desse tamanho com as curvas de distribuição de comprimento permitem determinar o estrato da população em que a pesca vem atuando com maior intensidade (BRANCO et al. 1999).

Na população de $X$. kroyeri da Armação do Itapocoroy, os machos atingiram tamanho de primeira maturação com comprimento total de $7,3 \mathrm{~cm}$ e comprimento de carapaça de 1,42 $\mathrm{cm}$, enquanto que nas fêmeas esse tamanho foi superior, com comprimento total de $7,9 \mathrm{~cm}$ e comprimento de carapaça de $1,60 \mathrm{~cm}$. Esses tamanhos foram alcançados com idade em torno de seis meses, independente do sexo.

O tamanho de primeira maturação em X. kroyeri, ao longo de sua área de distribuição no Brasil, apresenta variações inerentes aos processos de determinação ou padrões regionais de crescimento das populações. Assim, em Tamandaré, PE, o comprimento médio da carapaça das fêmeas corresponde a 1,98 cm (Coelho \& SAntos 1993), na região de Caravelas (BA) a 1,38 $\mathrm{cm}$ e todas as fêmeas capturadas acima de $1,7 \mathrm{~cm}$ encontravam-se maduras (SANTOS \& Ivo 2000). Enquanto que no Ceará o tamanho de primeira maturação das fêmeas aumentou para 2,50 cm de comprimento da carapaça (MotA-Alves \& Rodrigues 1977). No litoral de São Paulo, exemplares com tamanho inferior a 2,0 cm de comprimento da carapaça foram considerados imaturos (VIEIRA 1947), já para Severino-Rodrigues et al. (1993), os machos atingiram o tamanho de primeira maturação com um comprimento total de $6,2 \mathrm{~cm}$ e as fêmeas $\operatorname{com} 7,1 \mathrm{~cm}$.

Os resultados obtidos nesse estudo, estão entre os meno- res tamanhos e idade em que a população de $X$. kroyeri atinge a primeira maturação, registrado no litoral brasileiro, entretanto, a amplitude de comprimento total é compatível com a literatura.

As informações existentes sobre a reprodução de X. kroyeri são contraditórias. Embora seja consenso entre os autores, a ocorrência de exemplares com gônadas maduras ao longo do ano, sugerindo um amplo período de desova.

De acordo com os resultados obtidos por Coelho \& SANtos (1993), Mota-Alves \& Rodrigues (1977) e SANTos \& Ivo (2000), provavelmente a principal época de reprodução do camarão sete-barbas no Nordeste do Brasil ocorra entre os meses de dezembro a abril. Enquanto que nas regiões Sudeste e Sul do país, a espécie apresenta reprodução mais intensa entre setembro a março (Vieira 1947, Neiva \& Wise 1967, Tremel 1968).

A população de X. kroyeri da Armação do Itapocoroy, apresenta um amplo período de desova, estando de acordo com o padrão registrado. Entretanto, ocorrem dois picos de reprodução: o principal durante a primavera (outubro-dezembro) e um menos intenso de outono (abril-maio).

Em torno de $94,8 \%$ dos machos e $96,4 \%$ das fêmeas de X. kroyeri examinados apresentaram estômagos com alimento. Essa freqüência elevada de alimento observada, pode estar relacionada com o período de atividade da espécie, visto que as maiores taxas de capturas foram registradas durante as primeiras horas do dia.

A metodologia utilizada na análise quantitativa do conteúdo estomacal mostrou-se adequada, apesar das limitações impostas pelo tamanho de algumas presas e ação do aparato alimentar. Foi possível a identificação de 30 itens, quando considerando a ingestão não acidental da areia, componentes da dieta de $X$. kroyeri, mas, alguns autores dispõem de bons levantamentos faunísticos das regiões estudadas, ampliando as possibilidades de identificação a nível de espécie; por outro lado, esta identificação não é o mais importante e sim determinar o espectro alimentar das espécies e a relação entre elas (BRANCO \& VERANI 1997).

A ingestão de areia por $X$. kroyeri poderia ocorrer juntamente com as presas, o que reforçaria a hipótese de ingestão a acidental. Entretanto, esse item representou o segundo recurso mais explorado pela espécie. O sedimento marinho e algas são colonizados por uma gama de microrganismos, tais como Foraminiferida, Ostracoda, considerados presas de baixo valor energético.

Para Cortés \& CRIAles (1989) o item detrito contribuiu com as maiores freqüências de ocorrência na dieta de $X$. kroyeri da Costa Verde, Magdalena, Colômbia. Comportamento semelhante tem sido registrado em trabalhos com camarões peneídeos (Chong \& SASEKumar 1981). De acordo com os mesmos, detrito orgânico pode ser considerado como um componente na dieta quando outros itens alimentares estão ausentes ou reduzidos. Além disso, detrito particulado serve como substrato para microrganismos como bactérias, fungos e

Revista Brasileira de Zoologia 22 (4): 1050-1062, dezembro 2005 
protozoários, que provavelmente são importantes como alimento do substrato (Anderes 1982, Stoner \& Zimmerman 1988).

Variações sazonais nos tipos de itens e quantidade de alimento consumido por X. kroyeri na Armação do Itapocoroy, podem ser atribuídas a disponibilidade de presas ao longo do ano. Os Gammaridae com exceção do inverno, foram o principal componente, em termos de índice alimentar; enquanto que, MOND, areia, Crustacea, Foraminiferida, Polychaeta e Mollusca alternaram-se em importância entre as estações (BRAnco \& Moritz JR. 2001). Assim, o predomínio dos Gammaridae, provavelmente refletem a disponibilidade desse recurso no meio ambiente ou facilidade de captura e processamento desse tipo de presa.

Analisando-se os dados de desembarque total do camarão sete-barbas do IвАма (1995) para o litoral de Santa Catarina, procedente das frotas industrial e artesanal, em conjunto, durante o período de 1965 a 1994, constata-se uma tendência de crescimento até 1973, obtendo-se nesse ano uma produção recorde de 5.176t. A partir dessa época, ocorreu um período de oscilações até 1977, e de um novo incremento entre os anos de 1978 a 1982, seguido de flutuações com tendência decrescente na produção até atingir, em 1991, a produção de 762 t, relativamente superior a mínima (428t) obtida em 1965. Apesar desse declínio, nos últimos três anos, tem-se observado uma gradativa recuperação, alcançando em 1994 uma produção de 1.859t (Iвама 1995).

De acordo com Epagri/Ibama (1995), o pico de safra do camarão sete-barbas no litoral catarinense ocorre entre os meses de fevereiro a abril; nessa época, a produção média diária por embarcação da frota artesanal em 10 horas de pesca, pode alcançar até $100 \mathrm{~kg}$ de camarões.

Entre os conhecimentos requeridos no manejo de um recurso pesqueiro destaca-se o da abundância do estoque, visto que dimensiona a disponibilidade ou escassez do recurso. Dessa forma, a captura por unidade de esforço (CPUE- biomassa ou número) é o índice de abundância mais adequado no monitoramento pesqueiro do camarão sete-barbas. Mudanças nesse índice refletem acuradamente as flutuações temporais na abundância de camarões no estoque, como as observadas neste estudo. Apesar das flutuações sazonais nas taxas de captura durante os sete anos de coleta do sete-barbas, o esforço de pesca na Armação do Itapocoroy permaneceu relativamente estável, com uma média diária de 67 embarcações atuando em torno de 240 dias e capturando aproximadamente 130,82 toneladas/ano.

Estudos como o presente, analisando uma série temporal de dados são raros e de grande interesse, principalmente, tratando-se de um recurso econômico com relevância sóciocultural no litoral brasileiro. Assim, os dados oriundos desse trabalho, poderão contribuir na solução da atual controvérsia entre os pescadores artesanais e o Ibama, visto que, até o momento, as Portarias estabelecem a proibição temporária da pesca ou defeso de camarões no litoral Sudeste-Sul fundamentadas na proteção do camarão-rosa (Farfantepenaeus paulensis Pérez Farfante, 1967 e F. brasiliensis Latreille, 1817). Em função dos processos de migração dos estuários e lagoas costeiras para o mar, os pré-adultos dessas espécies percorrem as regiões de pesca do camarão sete-barbas (VALENTINI et al. 1991).

Atualmente o defeso do camarão (Portaria IBAMA n ${ }^{\circ} 171$, de 2/01/91) suspende a pesca entre os meses de fevereiro e maio de cada ano, este período coincide com a época de maior abundância do camarão sete-barbas no litoral Central e Norte de Santa Catarina (Tremel 1968, Epagri/Ibama 1995). Os resultados obtidos na Armação do Itapocoroy demonstram que as maiores taxas de captura, sempre ocorreram entre dezembro a maio, com os picos anuais alternando-se entre março e abril, e com o principal pulso reprodutivo na primavera (outubro a dezembro). Além disso, raramente foram registradas a ocorrência de camarão-rosa nas coletas direcionadas ao sete-barbas (BRANCO \& FrACASSO 2004). Para VALENTini et al. (1991), os valores crescentes da abundância nos anos de aplicação do defeso, associados à queda no esforço de pesca, justificariam a utilização da referida Portaria.

A não aplicabilidade das medidas prevista nessa Portaria, bem como sua falta de fundamentação biológica para o litoral Centro-Norte catarinense é reconhecida historicamente pelo conhecimento etnoecológico dos pescadores locais de camarão sete-barbas, e tem sido foco de conflitos permanentes com a atividade de fiscalização do Ibama, o qual tem aplicado sistematicamente a legislação em vigor.

Desta forma é natural que as comunidades pesqueiras artesanais que atuam sobre este recurso reivindiquem a alteração desse instrumento, nas áreas onde esteja comprovada cientificamente a sua inaplicabilidade. Por outro lado, existe a necessidade de ordenamento da pescaria especificamente voltada ao camarão sete-barbas, que deverá incorporar as especificações biológicas de seu ciclo de vida, desassociado de ambientes estuarinos.

\section{REFERÊNCIAS BIBLIOGRÁFICAS}

Anderes, B.L. 1982. Composición de la base alimentaria de los camarones rosado y blanco Penaeus notialis y Penaeus schmitti en la enseada de la Broa. Revista Cubana de Investigaciones Pesqueras. Havana, 8 (1): 51-65.

Bertalanffy, L. VON. 1938. A quantitative theory of organic growth. Humman Biology, Detroit, 10 (2): 181-213.

Boschi, E.E. 1969. Estudio biológico pesquero del camarón Artemesia longinaris Bate, de Mar del Plata. Boletin Biologia Marina, Mar del Plata, Argentina, 18: 1-47.

Branco, J.O. \& H.A.A. Fracasso. 2004. Ocorrência e abundância da carcinofauna acompanhante na pesca do camarão setebarbas, Xiphopenaeus kroyeri Heller (Crustácea, Decapoda), na Armação do Itapocoroy, Penha, Santa Catarina, Brasil. Revista Brasileira de Zoologia, Curitiba, 21 (2): 295-301.

Branco, J.O. \& H.C. Moritz-Jr. 2001. Alimentação natural do camarão sete-barbas, Xiphopenaeus kroyeri (Heller) (Crustácea, Decapoda), na Armação do Itapocoroy, Penha, Santa Catarina. Revista Brasileira de Zoologia, Curitiba, 18 (1): 53-61.

Revista Brasileira de Zoologia 22 (4): 1050-1062, dezembro 2005 
Branco, J.O. \& J.V. Verani. 1997. Dinâmica da alimentação natural de Callinectes danae Smith (Decapoda, Portunidae) na Lagoa da Conceição, Florianópolis, Santa Catarina, Brasil. Revista Brasileira de Zoologia, Curitiba, 14 (4): 1003-1018.

Branco, J.O.; M.J. Lunardon-Branco \& A. De Fenis. 1994. Crescimento de Xiphopenaeus kroyeri (Heller,1862) (Crustacea: Natantia: Penaeidae) da região de Matinhos, Paraná, Brasil. Arquivos de Biologia e Tecnologia, Curitiba, 37 (1): 1-8.

Branco, J.O.; M.J. Lunardon-Branco; F.X. Souto \& C.R. Guerra. 1999. Estrutura populacional do camarão sete-barbas Xiphopenaeus kroyeri (Heller, 1862), na foz do rio Itajaí-Açú, Itajaí, SC, Brasil. Brazilian Archives of Biology and Technology, Curitiba, 42 (1): 115-126.

Branco, J.O.; J.R.R. Braun \& J.R. Verani. 2001. Seasonal variation in the abundance of seabirds in areas of mariculture. Brazilian Archives of Biology and Technology, Curitiba, 44 (4): 395-399.

Branco, J.O.; M.J. Lunardon-Branco \& F.X. Souto. 2002. Estrutura populacional de Portunus spinimanus Lateille (Crustacea, Portunidae) na Armação do Itapocoroy, Penha, Santa Catarina, Brasil. Revista Brasileira de Zoologia, Curitiba, 19 (3): 731-738.

Chong, V.C. \& A. Sasekumar. 1981. Food and feeding habits of the white prawn Penaeus merguiensis. Marine Ecology Progress Series, Nordbunte, Germany, 5 (2): 185-191.

Coelho, P.A. \& M.C.F. SANTos. 1993. Época da reprodução do camarão-sete-barbas, Xiphopenaeus kroyeri (Heller, 1862) (Crustacea, Decapoda, Penaeidae) na região de Tamandaré, PE. Boletim Técnico Científico CEPENE, Rio Formoso, 1 (1): 171-186.

Cortés, M. \& M.M. Criales. 1989/90. Analisis del contenido estomacal del camaron titi Xiphopenaeus kroyeri (Heller) (Crustacea: Natantia: Penaeidae). Anales del Instituto de Investigaciones Marinas, Punta Betin, 19-20: 23-33.

D'InCÃo, F. 1984. Estudo sobre o crescimento de Penaeus (Farfantepenaeus) paulensis Pérez Farfante, 1967 da Lagoa dos Patos, RS, Brasil (Decapoda, Penaeidae). Atlântica, Rio Grande, 7: 73-84.

D’IncÃo, F.; H. VAlentini \& L.F. Rodrigues. 2002. Avaliação Da Pesca De Camarões Nas Regiões Sudeste E Sul Do Brasil: 19651999. Atlântica, Rio Grande, 24 (2): 103-116.

EPAGRI/IbAma. 1995. Situação sócio-econômica dos pescadores artesanais que operam na pesca de arrasto de camarões de Santa Catarina. Florianópolis, Empresa de Pesquisa Agropecuária e Extensão Rural de Santa Catarina, 17p.

Fransozo, A.; R.C. Costa; M.A.A. Pinheiro; S. Santos \& F.L.M. Mantelatto. 2000. Juvenile recruitment of seabob Xiphopenaeus kroyeri (Heller, 1862) (Decapada, Penaeidae) in the Fortaleza Bay, Ubatuba, SP, Brazil. Nauplis, Rio Grande, 8 (2): $179-184$.

Garcia, S. \& L. Le Reste. 1981. Life cicles, dynamics, exploitation and management of coast penaeid shrimp stocks. FAO Fisheries Technical Paper. Roma, 203: 1-215.
Holthuis, L.B. 1980. Shrimp and prawns of the world. An annoted catalogue of species of interest to fisheries. FAO Species Catalogue, Roma, 1: 1-261.

Івама. 1995. Relatório da reunião técnica de avaliação das pescarias de camarões das regiões Sudeste e Sul do Brasil, realizada de 06 a 10 de outubro de 1995, em Itajaí SC. Itajaí. Itajaí, IBAMA/CEPSUL, 38p.

IwAI, M. 1973. Pesca exploratória e estudo biológico sobre o camarão na costa Centro/Sul do Brasil com o Navio Oceanográfico "Prof. W. Besnard"em 1969-1971. São Paulo, SUDELPA, IOUSP, 71p.

Mello, J.T.C. 1973. Estudo populacional do "camarão-rosa" Penaeus brasiliensis (Latreille, 1817) e Penaeus paulensis Pérez Farfante 1967. Boletim do Instituto de Pesca, São Paulo, 2 (2): 19-65.

Mota-Alves, M.I. \& M.M. Rodrigues. 1977. Aspectos da reprodução do camarão-sete-barbas Xiphopenaeus kroyeri (Heller) (Decapoda, Macrura), na costa do Estado do Ceará. Arquivo de Ciência Marinha, Ceará, 17 (1): 29-35.

Nakagaki, J.M. \& M.L. Negreiros-Fransozo. 1998. Population biology of Xiphopenaeus kroyeri (Decapada: Penaeidae) from Ubatuba Bay, São Paulo, Brazil. Jornal of Shellfish Research, Maine, 17 (4): 931-935.

Nascimento, P.A.M. \& C.R. Poli. 1986. Curva de crescimento do camarão sete-barbas, Xiphopenaeus kroyeri (Heller, 1962), na Baía de Tijucas - Santa Catarina. In: Anais do I Seminário sobre Ciências do Mar da Universidade Federal de Santa Catarina. Florianópolis, vol. 1, p. 37-41.

NeIVA, G.S. \& J.P. Wise. 1967. A biologia e pesca do "camarão sete-barbas" da Baía de Santos, Brasil. Revista Nacional de Pesca, São Paulo, 1: 12-19.

PaIva, M.P. 1971. Tentativa de avaliação dos recursos pesqueiros do Nordeste brasileiro. Arquivo de Ciência Marinha, Ceará, 11 (1): 1-15.

Perez-Farfante, I. 1970. Diagnostic characters of juveniles of the shrimps Penaeus aztecus aztecus, $P$. duorarum duorarum, and P. brasiliensis (Crustacea, Decapoda, Penaeidae). Special Scientific Report Fisheries FAO, Rome, 599: 1-26.

Perez-Farfante, I. 1978. Srhimps and prawns, p. 40. In: W. Fisher (Ed.). FAO species identifications sheets for fishery purposes. Rome, FAO, Western Central Atlantic (Fishery Area 31), vol. 6.

SANTOS, E.P. 1978. Dinâmica de populações aplicada à pesca e piscicultura. São Paulo, HUCITEC, EDUSP, 129p.

Santos, M.C.F. \& P.A. Coelho. 1996. Estudo sobre Xiphopenaeus kroyeri (Heller, 1862) (Crustacea, Decapoda, Penaeidae) em Luis Correia, PI. Trabalhos Oceanográficos da Universidade Federal de Pernambuco, Recife, 24: 241-248.

SAntos, M.C.F. \& C.T.C. Ivo. 2000. Pesca, biologia e dinâmica populacional do camarão sete-barbas, Xiphopenaeus kroyeri (Heller, 1862) (Crustacea: Decapoda: Penaeidae), capturado em frente ao município de Caravelas (Bahia- Brasil). Boletim Técnico Científico CEPENE, Tamandaré, 8 (1): 131- 
164.

Santos, E.P.; G.S. Neiva \& Y. Schaeffer. 1969. Dinâmica da População do camarão-sete-barbas, Xiphopenaeus kroyeri (Heller) na Baía de Santos. Pescarias Pesquisas, São Paulo, 2 (2): 4155.

Severino-Rodrigues, E.; J.B. Pita; R. Graça-Lopes; J.A.P. Coelho \& A. Puzzi. 1993. Aspectos biológicos e pesqueiros do camarão sete-barbas (Xiphopenaeus kroyeri) capturado pela pesca artesanal no litoral do estado de São Paulo. Boletim do Instituto de Pesca, São Paulo, 19 (1): 67-81.

SOKAL, R.R. \& F.J. RoHLF. 1969. Biometry, the principles and practies of statistics in biological research. San Francisco, W.H. Freeman, 776p.

Stoner, A.W. \& R.J. Zimmerman. 1988. Food pathways associated with penaeid shrimps in a magrove-fringed estuary. Fish bulletin, Sacramento, 86 (3): 543-551.

SUDEPE-P.D.P. 1987. Relatório da VII reunião do grupo permanente de estudos sobre camarões da região sudeste/Sul. Itajaí, Ibama, 19p.

Tremel, E. 1968. Recursos camaroneiros da Costa de Santa Catarina, Brasil: resultados preliminares da pesquisa sobre o camarão-sete-barbas. Documentos Técnicos Carpas, Rio de Janeiro, 21: 1-6.

Valentini, H.; F. D’IncaO; L.F. Rodrigues; J.E.R. Neto \& L.G. Domit.
1991. Análise da pesca do camarão sete-barbas (Xiphopenaeus kroyeri) nas regiões Sudeste e Sul do Brasil. Atlântica, Rio Grande, 13 (1): 171-177.

VAzzolER, A.E.A.M. 1981. Manual de métodos para estudos biológicos de populações de peixes: reprodução e crescimento. Brasília, CNPq, Programa Nacional de Zoologia, $106 \mathrm{p}$.

VAzzolER, A.E.A.M. 1996. Biologia da reprodução de peixes teleósteos: teoria e prática. Maringá, EDUEM, 169p.

Vieira, B.B. 1947. Observações sobre a maturação de Xiphopenaeus kroyeri no litoral de São Paulo. Boletim do Museu Nacional, Rio de Janeiro, 74: 1-22.

Villela, M.J.; P.A. Costa \& J.L. Valentin. 1997. Crescimento e mortalidade de juvenis do camarão-rosa (Penaeus brasiliensis Latreille, 1817) na Lagoa de Araruama, Rio de Janeiro. Revista brasileira de Biologia, Rio de Janeiro, 57 (3): 487-499.

WALFORD, L.A. 1946. A new graphic method of describing the growth of animals. Biological Bulletin Marine Biological Laboratory, Massachusetts, 90 (2): 141-147.

Williams, A.B. 1965. Marine Decapod Crustacean of the Carolinas. Fishery bulletin, Sacramento, 65 (1): 1-298.

Zenker, H.H. \& J.L. Agnes. 1977. Distribuição do camarão-rosa Penaeus brasiliensis e Penaeus paulensis ao longo da costa Sudeste e Sul do Brasil. Série Documentos Técnicos, São Paulo, 21: 1-105.

Recebido em 11.IV.2005; aceito em 07.XI.2005. 